\title{
Analysis of mutations in the cystic fibrosis transmembrane regulator (CFTR) gene in patients with obstructive azoospermia
}

\author{
Andrea L.F. Bernardino, Cintia E. Lima and Mayana Zatz \\ Human Genome Research Center, Departamento de Biologia, Instituto de Biociências, \\ Universidade de São Paulo, São Paulo, Brazil.
}

\begin{abstract}
Congenital bilateral absence of the vas deferens (CBAVD) accounts for $1 \%-2 \%$ of sterility in men. A high incidence of mutations, as well as the involvement of the $5 \mathrm{~T}$ variant of the T tract length in intron 8 of the cystic fibrosis conductance regulator (CFTR) gene, have been previously described in males with CBAVD. Herein we report the screening for mutations and for the 5T variant of the CFTR gene in 17 patients with CBAVD and three others with non-CABVD obstructive azoospermia. In the CBAVD group, three patients (15\%) were compound heterozygotes for mutations, and five patients (25\%) had a mutation in one allele and the $5 \mathrm{~T}$ variant in the other; the $5 \mathrm{~T}$ variant was also present in two other patients, one of them being homozygous. The most frequent mutation was $\Delta \mathrm{F} 508$, present on five chromosomes (12.5\%). A novel missense mutation (A399D) was detected in a Japanese CBVAD patient. Our results yield further evidence for a strong association between male obstructive azoospermia caused by CBAVD and mutation/5T variant in the CFTR gene. The search for CFTR mutations in such patients is thus recommended for genetic counseling of couples who undergo assisted fertilization due to CBAVD.
\end{abstract}

Key words: CFTR mutations, obstructive azoospermia, male infertility.

Received: July 8, 2002; accepted: January 8, 2003.

\section{Introduction}

Congenital bilateral absence of vas deferens (CBAVD) accounts for approximately $6 \%$ of the cases of obstructive azoospermia. It is responsible for $1 \%-2 \%$ of cases of infertility in men and is also present in about $95 \%$ of male patients with cystic fibrosis (CF) (Jequier et al., 1985). CF is a common severe autosomal recessive disorder characterized by chronic obstructive pulmonary disease, pancreatic exocrine insufficiency, and elevated concentrations of electrolytes in sweat (Boat et al., 1989). Clinical manifestation varies greatly among patients, probably due, in part, to the multitude of disease-causing mutations in the CFTR gene. More than 980 mutations in the CFTR gene have been reported (Bernardino et al., 2000). In CF patients, the vas deferens, the tail and body of the epididymis, and the seminal vesicle are atrophic, fibrotic, or completely absent. The pathogenesis of these structural changes probably relates to early, often intrauterine, obstruction of the genital tract by inspissant secretions (Kaplan et al., 1968).

Send correspondence to Mayana Zatz. Rua do Matão, 277. Departamento de Biologia, Instituto de Biociências, Universidade de São Paulo, 05508-900 São Paulo, Brazil. E-mail: mayazatz@usp.br.
CBAVD is a genetically heterogeneous and complex disorder, involving mutations and variants of the CFTR gene in over $80 \%$ of cases (Dörk et al., 1997). Approximately $10 \%$ of CBAVD patients carry CF mutations on both chromosomes, but in most cases the mutations have been detected in just one of the CFTR alleles.

Genotype-phenotype correlation studies have associated CF mutations with male infertility caused by CBAVD, suggesting that this condition is primarily a genital form of CF (Anguiano et al., 1992; Chillón et al., 1995; Pignatti et al., 1996; Cohn et al., 1998; Sharer et al., 1998). Other studies have also shown that there is a strong association of the IVS8-T5 variant with CBAVD (Chu et al., 1993). In patients with CBAVD, the frequency of the $5 \mathrm{~T}$ variant is higher than in the general population. In some patients, homozygosity for this variant suffices to cause CBAVD and mild CF symptoms (Dörk et al., 1997). These data support the suggestion that the $5 \mathrm{~T}$ variant is a "very mild" CFTR mutation, specifically causing CBAVD (Zielenski et al., 1995).

In the present study we performed CFTR gene analysis on 20 patients who were referred to our center due to obstructive azoospermia, 17 of which had CBAVD. 


\section{Patients and Methods}

\section{Patients}

The present investigation was performed on a group of 20 unrelated men (ages 26 to 49 years) with obstructive azoospermia. Seventeen of them were found to have CBAVD. The diagnosis of CBAVD or obstructive azoospermia was based on scrotal examination, ultrasound and semen analysis. None had been diagnosed with CF or had any pulmonary problems, except for one patient who reported bronchitis in childhood. Nineteen patients were pancreatic-sufficient, and one had pancreatitis.

\section{DNA Analysis}

Mutation detection studies were carried out on all 27 exons and exon/intron boundaries of the CFTR gene by means of single-strand conformation polymorphism (SSCP) and heteroduplex analysis. A $100 \mathrm{ng}$ sample of genomic DNA was amplified under the following conditions: $20 \mathrm{mM}$ Tris- $\mathrm{HCl}$ ( $\mathrm{pH} 8.4$ ), $50 \mathrm{mM} \mathrm{KCl}, 1.5 \mathrm{mM}$ $\mathrm{MgCl}_{2}, 0.2 \mathrm{mM}$ of each primer, and 2 units of Taq polymerase (Gibco BRL) for 35 cycles. All PCR reactions were performed in a total volume of $10 \mu \mathrm{L}$. SSCP/heteroduplex analysis was performed according to the method described by Ravnik-Glavac et al. (1994). Abnormally migrating fragments were subsequently sequenced to confirm the presence of mutations. CFTR gene variants of the T tract length of intron 8 were investigated. Microsatellite IVS8 $\left(\mathrm{T}_{\mathrm{n}}\right)$ analysis was made by PCR, and the amplified fragments were subjected to electrophoresis at $1500 \mathrm{~V}$ for $4 \mathrm{~h}$ in a $6.5 \%$ denaturing polyacrylamide gel.

\section{Results}

Of the 17 patients with CBAVD, ten were found to carry mutations/variants: three $(17.7 \%)$ carried two CFTR mutations $(\Delta \mathrm{F} 508 / \mathrm{R} 117 \mathrm{H} ; \Delta \mathrm{F} 508 / \mathrm{P} 205 \mathrm{~S} ; \Delta \mathrm{F} 508 / \mathrm{L} 206 \mathrm{~W})$, five $(29.4 \%)$ had one CFTR mutation and the $5 \mathrm{~T}$ variant in the second allele (A399D/5T; W1282X/5T; two $\Delta$ F508/5T; L206W/5T), one patient was homozygous, and another one was heterozygous for the $5 \mathrm{~T}$ variant. In seven CBAVD patients and in the three patients with non-CBAVD obstructive azoospermia no mutation/variant was detected.

Overall, seven different mutations, including the $5 \mathrm{~T}$ variant, were detected by screening the 27 CFTR exons and exon/intron boundaries. The $5 \mathrm{~T}$ variant was the most common mutated allele $(7 / 17)$, and $\Delta \mathrm{F} 508$ was the second most frequent (5/17). One novel mutation, A399D, was found: this $\mathrm{C} \rightarrow \mathrm{A}$ transition at position 399 in exon 8 leads to the substitution of alanine for aspartic acid. This mutation was detected in a 39-year-old Japanese CBAVD patient, who also carried the $5 \mathrm{~T}$ variant at the other allele.

The patient who reported childhood bronchitis was found to carry two mutations $(\Delta \mathrm{F} 508 / \mathrm{P} 205 \mathrm{~S})$. This was also the case of the patient with pancreatitis ( $\Delta$ F508/L206W).

\section{Discussion}

The aim of this study was to determine the frequency of mutations/variants of the CFTR gene in Brazilian patients with CBAVD or with non-CBAVD obstructive azoospermia. Among the 17 patients with CBAVD, eight were compound heterozygotes for mutations, or for a mutation and the 5T variant, and two patients carried only the 5T variant, one of them being homozygous for it. No alterations were found in seven patients with CBAVD and in the three azoospermic patients without CBAVD. A high number of different CFTR mutations have been reported in patients with CBAVD (Chillón et al., 1995; Dörk et al., 1997; Mak et al., 1999; Casals et al., 2000). Most of these mutations correspond to amino acid changes or splice site mutations, and they are likely to cause a mild CF phenotype (Casals et al., 2000). However, less than 60\% of these mutations are of the same types as those found in the patients with CF (Casals et al., 1997). Thus, in the majority of CBAVD patients, a complete screening of the CFTR gene is needed to identify mutations in one or both alleles. In the 17 CBAVD patients of our sample, we detected seven different mutations, including the $5 \mathrm{~T}$ variant. This variant was found at a frequency of $23.5 \%$, which is in accordance with previous reports (Chillón et al., 1995, Casals et al., 2000), thus confirming its association with CBAVD. The $\Delta \mathrm{F} 508$ deletion was found on five chromosomes and was the second most frequent mutation. Other five mutations were identified (R117H, P205S, L206W, A399D, and W1282X). The L206W mutation, found in two out of the 17 CBAVD patients, had previously only been detected in two Brazilian CF patients of a CFTR gene screening study with 160 patients (Bernardino et al., 2000). This preliminary observation suggests that the $\Delta \mathrm{F} 508$ and L206W mutations, together with the $5 \mathrm{~T}$ variant, should be the first ones to be analyzed in Brazilian CBAVD patients, but the frequency of the L206W mutation should be confirmed in a larger sample. The A399D mutation identified in a Japanese patient was unexpected, since mutations in the CFTR gene are very rare in this ethnic group (Beaudet et al., 1989).

The 5T variant in intron 8 of the CFTR gene leads to a higher proportion of mRNA transcripts lacking exon 9 than the other variants, $7 \mathrm{~T}$ and $9 \mathrm{~T}$. Consequently, the $5 \mathrm{~T}$ variant produces abnormally low levels of the CFTR protein (Chu et al., 1993; Chillón et al., 1995). On the other hand, the observation that in the majority of the CBAVD cases the mutations have been found in only one of the CFTR alleles is still not well understood. Studies on CFTR protein function show that $6 \%-10 \%$ of the normal levels of this protein are sufficient for normal ion transport (Chu et al., 1993); therefore, carrying one mutation only would not lead to the $\mathrm{CF}$ phenotype. A possible explanation is that the second alter- 
ation could be located at non-screened intronic, promoter, or regulatory sites, resulting in a CFTR protein with normal structure but low levels of expression, thus altering the development of susceptible tissues, such as the vas deferens and epididymis (Culard et al., 1999; Casals et al., 1995; Anguiano et al., 1992). Interestingly, we recently examined a male patient presenting with alcoholic pancreatitis, who carried two CF mutations and had fathered two children (unpublished observation). This indicates that some male patients may still be fertile, even carrying mutations at both $\mathrm{CF}$ alleles.

In summary, our data provide further evidence of a strong association between male obstructive azoospermia caused by CBAVD and mutations/5T variant in the CFTR gene in Brazilian patients. In addition to diagnosis confirmation, the identification of mutations in these patients provides important information for the genetic counseling of couples, prior to assisted fertilization.

\section{Acknowledgments}

The collaboration of the following persons is gratefully acknowledged: Dr. Agnaldo Cedenho, Dr Paulo Serafini, Dr. Eduardo Motta, Dr. Sidney Glina, Dr. Elvio Tognoti, Dr. Jorge Halak. Our special thanks to all patients who collaborated with his study. This work was supported by grants from FAPESP/CEPID (Fundação de Amparo a Pesquisa do Estado de São Paulo), CNPq (Conselho Nacional de Desenvolvimento Científico e Tecnológico), and PRONEX (Programa de Apoio a Núcleo de Pesquisas).

\section{References}

Anguiano A, Oates RD, Amos JA, Dean M, Gerrard B, Stewart C et al. (1992) Congenital Bilateral Absence of the Vas Deferens: a primarily genital form of cystic fibrosis. JAMA 267(13):1794-1797.

Beaudet A (1989) Cystic Fibrosis. In: Scriver CR, Beaudet AL, Sly WS, Valle D (eds) The Metabolic Basis of Inherited Disease, $6^{\text {th }}$ ed Mc Graw-Hill, New York, pp 2649-2680.

Bernardino ALF, Ferri A, Passos-Bueno MR, Nakaie CMA, Damaceno N and Zatz M (2000) Molecular analysis in Brazilian cystic fibrosis patients reveals five novel mutations. Genetic testing 4:69-74.

Boat TF, Welsh MJ and Baudet AL (1989) Cystic Fibrosis. In: Scriver CR, Beaudet AL, Sly WS, Valle D (eds). The Metabolic Basis of Inherited Disease, $6^{\text {th }}$ ed Mc Graw-Hill, New York, pp 2649-2680.

Casals T, Bassas L, Ruiz-Romero, Chillón M, Giménez T, Ramos MD et al. (1995) Extensive analysis of 40 infertile patients with congenital absence of the vas deferens: in $50 \%$ of cases only one CFTR allele could be detected. Hum Genet 95:205-211.

Casals T, Bassas L, Egozcue S, Ramos MD, Giménez, J, Segura A et al. (2000) Heterogeneity for mutations in the CFTR gene and clinical correlations in patients with congenital absence of the vas deferens. Hum Reprod 15(7):1476-1483.

Chillón M, Casals T, Mercier B, Bassas L, Lissens W, Silber S et al. (1995) Mutations in the cystic fibrosis gene in patients with congenital absence of the vas deferens. N Engl J Med 332(22):1475-1480.

Chu C-S, Trapnell BC, Curristin S, Cutting GR and Crystal RG (1993) Genetic basis of variable exon 9 skipping in cystic fibrosis transmembrane conductance regulator mRNA. Nat Genet 3:151-156.

Cohn JA, Friedman KJ, Noone PG, Knowles MR, Silverman LM and Jowell PS (1998) Relation between mutations of the cystic fibrosis gene and idiopathic pancreatitis. N Engl J Med 339:653-658.

Culard J-F, Degeorges M, Costa P, Laussel M, Razakatzara G and Navratil H (1994) Analysis of the whole CFTR coding region and splice junctions in azoospermic men with congenital bilateral aplasia of epididymis or vas deferens. Hum Genet 93:467-470.

Dörk T, Dworniczak B, Aulehla-Schalz C, Wieczorek D, Böhm I and Mayerova A (1997) Distinct spectrum of CFTR gene mutations in congenital absence of vas deferens. Hum Genet 100:365-377.

Jequier AM, Ansell ID and Bullimore NJ (1985) Congenital absence of the vas deferens presenting with infertility. J Androl 6:15-19.

Kaplan E, Swachman H, Permutter AD, Rule A, Khaw K-T and Holsclaw DS (1968) Reproductive failure in males with cystic fibrosis. N Engl J Med 279:65-69.

Mak V, Zielenski J, Tsui L-C, Durie P, Zini A, Martin S et al. (1999) Proportion of cystic fibrosis gene mutation not detected by routine testing in men with obstructive azoospermia. JAMA 281:2217-2224.

Pignatti PF, Bombieri C, Benetazzo M, Casartelli A, Trabetti E, Gilè LS et al. (1996) CFTR gene variant IVS8-5T in disseminated bronchiectasis. Am J Hum Genet 58:889-892.

Ravnik-Glavac M, Glavac D and Dean M (1994) Sensitivity of single-strand conformation polymorphism and heteroduplex method for mutation detection in the cystic fibrosis gene. Hum Mol Genet 3(5):801-807.

Sharer N, Schwarz M, Malone G, Howarth A, Painter J, Super M et al. (1998) Mutations of the cystic fibrosis gene in patients with chronic pancreatitis. N Engl J Med 339:645-652.

Zielenski J, Patrizio P, Corey M, Handelin B, Markiewicz D, Asch R et al. (1995) CFTR gene variant for patients with congenital absence of vas deferens. Am J Hum Genet 57:958-960.

Associate Editor: Angela M. Vianna-Morgante 